\title{
Twisted nanoribbons from a RGD-bearing cholic acid derivative
}

\author{
Leana Travaglini ${ }^{\mathrm{a}}$, Cesare Giordano ${ }^{\mathrm{b}}$, Andrea D’Annibale ${ }^{\mathrm{a}}$, Marta Gubitosi ${ }^{\mathrm{a}}$, Maria Chiara di Gregorio ${ }^{\mathrm{a}}$, \\ Karin Schillén $^{\mathrm{c}}$, Azzurra Stefanucci ${ }^{\mathrm{d}}$, Adriano Mollica ${ }^{\mathrm{d}}$, Nicolae Viorel Pavel ${ }^{\mathrm{a}}$, Luciano Galantini ${ }^{\mathrm{a}, *}$ \\ a Department of Chemistry, Sapienza University of Rome, P.le A. Moro 5, 00185 Rome, Italy \\ ${ }^{\mathrm{b}}$ Institute of Molecular Biology and Pathology, CNR, P.le A. Moro 5, 00185 Roma, Italy \\ c Division of Physical Chemistry, Department of Chemistry, Center for Chemistry and Chemical Engineering, Lund University, SE-221 00 Lund, Sweden \\ 'Department of Pharmacy, University of Chieti-Pescara "G. d'Annunzio", Via dei Vestini 31, 66100 Chieti, Italy
}

\section{A R T I C L E I N F O}

Article history:

Received 26 April 2017

Received in revised form 5 July 2017

Accepted 29 July 2017

Available online $\mathrm{xxx}$

Keywords:

RGD amphiphiles

Supramolecular nanoribbons

Self-assembly

Bile acids

\begin{abstract}
A B S T R A C T
In light of the biomedical interest for self-assembling amphiphiles bearing the tripeptide Arg-Gly-Gly (RGD), a cholic acid derivative was synthesized by introducing an aromatic moiety on the steroidal skeleton and the RGD sequence on the carboxylic function of its chain 17-24, thus forming a peptide amphiphile with the unconventional rigid amphiphilic structure of bile salts. In aqueous solution, the compound self-assembled into long twisted ribbons characterized by a very low degree of polydispersity in terms of width $(\approx 25 \mathrm{~nm})$, thickness $(\approx 4.5 \mathrm{~nm})$ and pitch $(\approx 145 \mathrm{~nm})$. It was proposed that in the ribbon the molecules are arranged in a bilayer structure with the aromatic moieties in the interior, strongly involved in the intermolecular interaction, whereas the RGD residues are located at the bilayer-water interface. The nanostructure is significantly different from those generally provided by RGD-containing amphiphiles with the conventional peptide-tail structure, for which fibers with a circular cross-section were observed, and successfully tested as scaffolds for tissue regeneration. From previous work on the use of this kind of nanostructures, it is known that features like morphology, rigidity, epitope spacing and periodicity are important factors that dramatically affect cell adhesion and signaling. Within this context, the reported results demonstrate that bile salt-based peptide surfactants are promising building blocks in the preparation of non-trivial RGD-decorated nanoaggregates with well-defined morphologies and epitope distributions.
\end{abstract}

\section{Introduction}

Molecular self-assembly is widely recognized as an attractive and versatile bottom up approach to construct nanomaterials for nanotechnology and nanoscience. Molecules spontaneously self-assemble into large and ordered arrays of multiple length scales, giving a wide variety of nanostructures. Depending on the structural units and the experimental conditions (e.g. $\mathrm{pH}$, solvent, temperature) the shape and the characteristic self-association properties of these aggregates can be tailored to address specific functions [1-4].

In this regard, amphiphilic molecules containing a peptide sequence are particularly promising building blocks in designing new materials for biotechnology and biomedicine. These compounds are constituted by a hydrophilic peptide motif conjugated to a structural

\footnotetext{
* Corresponding author.

Email address: luciano.galantini@uniroma1.it (L. Galantini)
}

hydrophobic unit. The self-assembly of these molecules is driven by the intrinsic amphipathic nature and by specific interactions arising from the presence of amino acids, and their characteristic functional groups.

The potential of these compounds lies in their extreme versatility. Due to the chemical diversity of amino acids, proper sequences in the peptide motif can be chosen to provide the molecule with the ability to respond to external triggers. Moreover, the self-assembly can be tuned by properly choosing the hydrophobic unit and the hydrophilic peptide (amino acid sequence, charge, branching, length). Finally, the introduction of biologically active subunits can be exploited for developing biomaterials to serve in biomedicine or bioengineering, for instance as scaffolds in tissue regeneration or carriers in drug delivery $[5,6]$.

The features mentioned above collectively allow peptide-based amphiphiles to provide a wide range of self-assembled architectures, which are characterized by a high degree of order at the nanoscopic level, able also to impart functionality to the entire structure. Differ- 
ent supramolecular structure, such as ribbons, tapes, rod-like micelles and fibers to mention a few have been reported and studied for specific applications. In the last fifteen years extensive efforts have been devoted to the investigation of peptide-based amphiphiles, and a comprehensive overview of their self-assembly properties and applications is provided by recent reviews [7-9]. The interest is still high especially when it comes to self-assembling units containing biologically active amino acid sequences such as Arg-Gly-Asp (RGD). This tripeptide is well-known for its biological role: being found in many extracellular matrix (ECM) proteins, responsible for binding integrin, the RGD epitope is the most common recognition motif involved in cell adhesion processes [10,11]. Numerous RGD-based amphiphiles have been investigated and their assemblies challenged as drug carriers or scaffolds for tissue regeneration [12-24].

It has been observed lately that the interface between cells and materials is a critical component in the design of scaffolds and recent work has revealed that receptor-mediated cell adhesion and signaling are critically influenced by several physical properties of the adhesive surface, i.e. morphology, rigidity and epitope spacing $[25,26]$. For instance, the influence of the periodicity of RGD-labeled nanostructures on the differentiation of stem cells has been proven [27], as well as the effect of the morphology of self-assembled multivalent RGD-peptide arrays on nanoscale binding events [28]. For cell adhesion, peptide-containing self-organized biomaterials have drawn attention because of their ability to provide controlled and high density epitope distributions. Due to this tunable feature and the ability to generate a variety of supramolecular architectures these materials could be also attractive models to better understand the interactions between RGD-based nanostructures and integrins.

The self-assembly behaviors of peptide based amphiphiles can be further enriched by introducing complex hydrophobic units derived from bile acid (BA) skeletons. BAs are natural surfactants with characteristic self-assembly features. They have a rigid and curved steroidal backbone and a specific distribution of polar and non-polar moieties. This results in ordered aggregates that can have different size and shape, such as globular, rod- or fiber-like and tubular, depending on the type of BA and on the experimental conditions [29-33]. In addition, synthetic derivatives of BAs showing a different hydrophilic-hydrophobic balance can provide complex supramolecular structures and self-assembly behavior that cannot be observed for the precursors $[30,34]$. Molecules that arrange into tubules are often observed. In some cases, tubules can present stimuli-responsive features as well as tunable size or charge [35-42]. A plentitude of low molecular weight gelators formed by BA derivatives have been also investigated [30,43-46].

In this framework, we reported in this work the preparation and characterization of the aggregation behavior of the novel compound N-3 $\beta$-(4-t-Butylbenzoylamine)-(7 $\alpha, 12 \alpha$-dihy-

droxy-5 $\beta$-cholan-24-oyl)-( $S)$-arginine- $(S)$-glycine- $(S)$-aspartic acid (RGD-tbutPhC). The molecular structure is depicted in Fig. 1.

To design our new compound, we chose as the main skeleton the $t$-butylphenyl amide derivative of cholic acid (H-tbutPhC), also shown in Fig. 1. It was considered particularly suitable, as it ensured a sufficient hydrophobicity and presented by itself a unique self-assembly. In fact, in bicarbonate buffer $\mathbf{H}$-tbutPhC forms fibers that reversibly interconvert into tubules through a temperature-triggered process. As the temperature is raised above $35-37{ }^{\circ} \mathrm{C}$ tubules are formed with a diameter of ca. $450 \mathrm{~nm}$ and length up to several $\mu \mathrm{m}$. Tubules are also observed at lower temperature in cases where high concentrations of buffer are used [47,48].

The self-assembly behavior of RGD-tbutPhC was fully investigated in mild alkaline conditions by means of circular dichroism
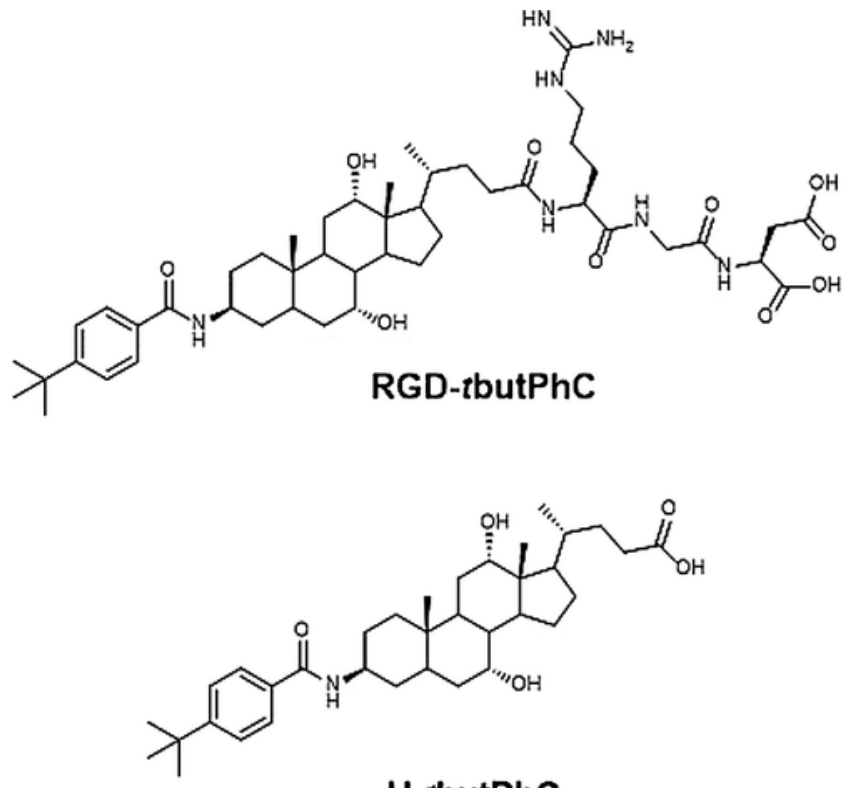

H-tbutPhC

Fig. 1. Molecular structure of the derivative RGD-tbutPhC and of the $t$-butylphenyl amide derivative of cholic acid $\mathbf{H}$-tbutPhC.

(CD), UV absorption spectroscopy, cryogenic transmission electron microscopy (cryo-TEM), small angle X-ray scattering (SAXS) and static light scattering (SLS).

\section{Materials and methods}

\subsection{Synthesis of the derivatives}

The derivative RGD-tbutPhC was synthesized following the synthetic route depicted in Scheme 1, the key step being the merging of $\mathbf{1}$ and $\mathbf{H}$-tbutPhC.

Compound 1 was prepared according to standard procedures for solution phase peptide synthesis and using a Fmoc-/ $t \mathrm{Bu}$ - orthogonal linkage/cleavage strategy [49]. Reaction between Fmoc-Arg(Pbf)-OH and $\mathrm{H}-\mathrm{Gly}-\mathrm{OMe} \cdot \mathrm{HCl}$ gave the dipeptide 2 . The selective hydrolysis in alkaline conditions of the ester group afforded the compound 3 [50,51]. Subsequent reaction with $\mathrm{H}-\mathrm{Asp}(\mathrm{O} t \mathrm{Bu})-\mathrm{O} t \mathrm{Bu} \cdot \mathrm{HCl}$ gave 4, from which 1 was obtained upon selective cleavage of the Fmoc protecting group. The key step of the synthetic pathway was the preparation of 5, through condensation between $\mathbf{1}$ and $\mathbf{H}-\mathbf{t b u t P h C}$, which was synthesized according to a reported procedure [52]. Compound $\mathbf{5}$ was purified by silica gel chromatography (see ESI for details), then completely deprotected using TFA as a cleavage agent, and purified affording RGD-tbutPhC as a TFA salt. The tripeptide RGD was also prepared for comparison through complete deprotection of $\mathbf{1}$. The details of the synthesis, the characterization of the compounds and all the abbreviations used for chemicals and solvents are reported in the Supplementary Information.

\subsection{Sample preparation}

RGD-tbutPhC did not dissolve either in pure bi-distilled $\mathrm{H}_{2} \mathrm{O}$ $(\mathrm{pH}=5.9)$ or in acidic conditions. Its self-assembly was therefore investigated in alkaline media. In the same conditions the solutions of RGD and $\mathbf{H}$-tbutPhC were also analyzed for comparison. The $\mathrm{pH}$ was adjusted by using titrated solution of sodium carbonate/bicarbon- 
<smiles>N=C(NCCC[C@H](NC(F)F)C(=O)O)Nc1ccccc1</smiles><smiles>COC(=O)CNC(=O)[C@H](CCCNC(=N)Nc1ccccc1)NC(F)(F)F</smiles><smiles>N=C(NCCC[C@H](NC(F)F)C(=O)NCC(=O)O)Nc1ccccc1</smiles>

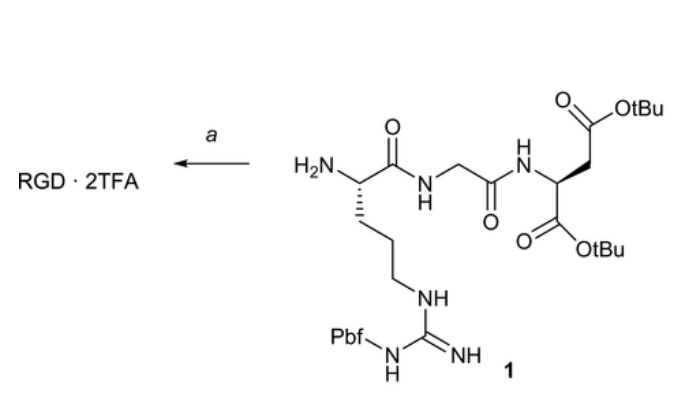<smiles>N#CC1CCCCC1</smiles><smiles>CCCCOC(=O)CC(NC(=O)CNC(=O)[C@H](CCCNC(=N)Nc1ccccc1)NC(F)(F)F)C(=O)OCCCC</smiles>

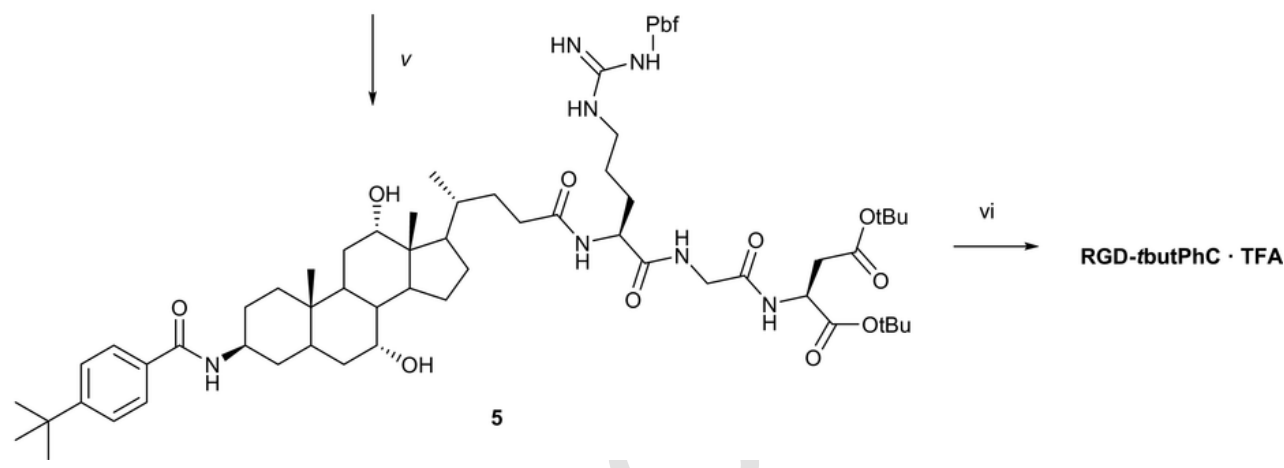

Scheme 1. i) $\mathrm{HCl} \cdot \mathrm{H}-\mathrm{Gly}-\mathrm{OMe}$, EDC, $\mathrm{HOBt}$, NMM, dry $\mathrm{CH}_{2} \mathrm{Cl}_{2}$, r.t., 16 h, $79 \%$; ii) LiOH, $\mathrm{H}_{2} \mathrm{O}, \mathrm{CaCl}_{2}$, $i$-PrOH, THF, r.t., 1 h, $89 \%$; iii) $\mathrm{HCl} \cdot \mathrm{H}-\mathrm{Asp}(\mathrm{O} t \mathrm{Bu})-\mathrm{O} t \mathrm{Bu}, \mathrm{EDC}$, $\mathrm{HOBt}$, $\mathrm{NMM}$, dry $\mathrm{CH}_{2} \mathrm{Cl}_{2}$, r.t., 16 h, 77\%; iv) DBU, $\mathrm{CH}_{2} \mathrm{Cl}_{2}$, r.t., 20 min, 89\%; v) H-tbutPhC, EDC, HOBt, NMM, dry $\mathrm{CH}_{2} \mathrm{Cl}_{2}$, r.t., 16 h, 78\%; vi) TFA/ $\mathrm{H}_{2} \mathrm{O} / \mathrm{TIS} 95: 2.5: 2.5$, r.t., 3 h, $18 \%$; a) TFA $\mathrm{H}_{2} \mathrm{O} / \mathrm{TIS} 95: 2.5: 2.5$, r.t., 3 h, $84 \%$.

ate buffers $(\mathrm{pH}$ 10.0) at a total concentration of $\left[\mathrm{Na}_{2} \mathrm{CO}_{3}\right]+\left[\mathrm{NaHCO}_{3}\right]=60.0 \times 10^{-3} \mathrm{M}$. All the experiments were carried out on solutions with a solute concentration of $5.0 \times 10^{-3} \mathrm{M}$, unless otherwise stated.

\subsection{UV-vis absorption and circular dichroism (CD)}

UV-vis and CD spectra were recorded simultaneously on a JASCO model 715 and reported in molar extinction coefficient $\varepsilon$ and molar ellipticity $[\Theta]$, respectively, after correction for the solvent contribution. The spectra were recorded in the wavelength $\lambda$ range $195-350 \mathrm{~nm}$, by using quartz cuvettes with path length $0.1 \mathrm{~mm}$. The spectral resolution was $1 \mathrm{~nm}$. The reported spectra were the result of three scans.

\subsection{Cryogenic transmission electron microscopy (cryo-TEM)}

Vitrification of the cryo-TEM sample was carried out using a controlled environment vitrification system [53], keeping the relative humidity close to saturation at around $26^{\circ} \mathrm{C}$. A thin film of the dispersion on a lacey carbon-coated copper grid was rapidly vitrified by plunging into liquid ethane $\left(-180^{\circ} \mathrm{C}\right)$ and stored in liquid nitrogen before the examination. The micrographs were recorded using a Philips CM120 Bio TWIN electron microscope equipped with a
Gatan MSC791 cooled-CCD camera detection system, operating at $120 \mathrm{kV}$, under low electron dose conditions. The values of width and twist pitch of the ribbons have been determined using the free software ImageJ.

\subsection{Small angle $X$-ray scattering (SAXS)}

The SAXS measurements were performed on the SAXSlab instrument (JJ X-ray, Skovlunde, Denmark). The instrument had a 2D $300 \mathrm{~K}$ Pilatus detector from Dectris (Dectris Ltd., Baden, Switzerland) and a Genix 3D X-ray source (Xenocs SA, Sassenage, France). The $\mathrm{X}$-ray wavelength $\lambda$ was $1.54 \AA$. The two-dimensional SAXS patterns were processed using the Fit2D software [54]. All the scattering intensities $I(q)$ were recorded within the range of $0.07<q<2.1 \mathrm{~nm}^{-1}$ of the scattering vector $q=(4 \pi \sin \theta) / \lambda$ (where $2 \theta$ is the scattering angle) and corrected for solvent contribution.

The SAXS patterns were analyzed by means of a model-based fit that uses the form factor $P(q)$ expression for long parallelepiped systems [55]. The parallelepiped model is implemented in SASview software. The indirect Fourier transform (IFT) method, developed in the ATSAS program [56], was used to analyze the cross-section profile of the aggregates, and to extract the cross-section pair correlation function $p_{c}(r)$. An integral over this function allowed for the estimation of the radius of gyration of the cross-section $R_{g c}$, whereas the 
cross-section maximum distance $D_{m c}$ was inferred as the distance at which the function vanished. The Guinier plots for $\operatorname{rods} \ln [q I(q)]$ vs $q^{2}$ and flat particles $\ln \left[q^{2} I(q)\right]$ vs $q^{2}$ were also used to analyze the SAXS curve and to estimate $R_{g c}$ and the gyration thickness $R_{g t}$, respectively. The thickness $T$ was determined by using the relation $R_{g t}{ }^{2}=T^{2} / 12$.

\subsection{Static light scattering (SLS)}

SLS measurements were performed by using a Brookhaven instrument constituted by a BI-2030AT digital correlator with 136 channels and a BI-200SM goniometer. The light source was a Uniphase solid-state laser system, model 4601, operating at $532 \mathrm{~nm}$. During the measurements, the temperature of the samples was kept constant within $0.5^{\circ} \mathrm{C}$ by a circulating water bath. The solutions were thermally equilibrated at each set temperature for at least $30 \mathrm{~min}$ prior to the measurement.

\section{Results and discussion}

The solution behaviour of RGD-tbutPhC was investigated in the presence of carbonate/bicarbonate buffer at $\mathrm{pH}$ 10.0, thus reproducing analogous conditions to those used in our previous work on the precursor H-tbutPhC $[47,48]$. This allowed for a comparison of the self-assembly properties of RGD-tbutPhC and $\mathbf{H}-\boldsymbol{t}$ butPhC thus assessing the influence of the peptide moiety on the aggregation process. The samples were turbid, clearly showing scattering due to the presence of large aggregates (Fig. S1). Elucidation of the aggregate structures started by recording the UV absorption and CD spectra.

The UV spectrum of the RGD-tbutPhC solution (Fig. 2a) showed a main band at $195 \mathrm{~nm}$ and a lower one at $240 \mathrm{~nm}$. Only a slight decrease of the intensities of peaks was observed upon increase of the temperature. A very similar UV profile was observed for $\mathbf{H}$-tbutPhC, whereas for the RGD peptide solution only a shoulder of significant absorbance was recorded at the lowest wavelength $(<230-240 \mathrm{~nm})$. Therefore, the comparison of the spectra of the three compounds (Fig. $2 \mathrm{~b}$ and $\mathrm{c}$ ) suggested that in the case of RGD-tbutPhC the RGD peptide significantly contributed only to the main band with the $n-\pi^{*}$ transitions and the tail of the $\pi-\pi^{*}$ transitions of peptide bonds and carboxylic groups. By contrast, phenylamide residue transitions contributed both to this band, mainly with $\pi-\pi^{*}$ transitions of aromatic and amide groups, and to the second weaker band, only with $\pi-\pi^{*}$ transitions of the aromatic group. The CD spectra of RGD-tbutPhC solutions recorded at $20^{\circ} \mathrm{C}$ (Fig. 3a) presented three recognizable bands, one band at $205 \mathrm{~nm}$ with negative $\theta$ values, one with positive values at $240 \mathrm{~nm}$ and a less intense negative band at $270 \mathrm{~nm}$. The intensity of the peaks decreased gradually upon increase of the temperature, probably due to a gradual breaking of the aggregates. This was confirmed by SLS measurements, as the scattered intensity recorded at $\theta=90^{\circ}$ (Fig. S2) decreased gradually upon increase of temperature. The process of breaking of the aggregates was reversible, as the $\mathrm{CD}$ spectrum recorded again after $1 \mathrm{~h}$ on the same sample cooled down to $20^{\circ} \mathrm{C}$, showed all the peaks with their original intensity (Fig. 3a). To better understand the contribution of both the moieties involved in the self-assembly, it was necessary to compare these dichroic profiles with those recorded on solutions prepared in the same conditions of both H-tbutPhC sodium salt and RGD (Fig. $3 \mathrm{~b}$ and $\mathrm{c}$ ). The dichroic profiles of the $\mathbf{H}-\mathbf{t b u t P h C}$ sodium salt were recorded on a $2.0 \times 10^{-3} \mathrm{M}$ solution at different temperatures using a concentration of buffer $\left(60.0 \times 10^{-3} \mathrm{M}\right)$ in which the tubules are present already at room temperature. It was possible to notice that a

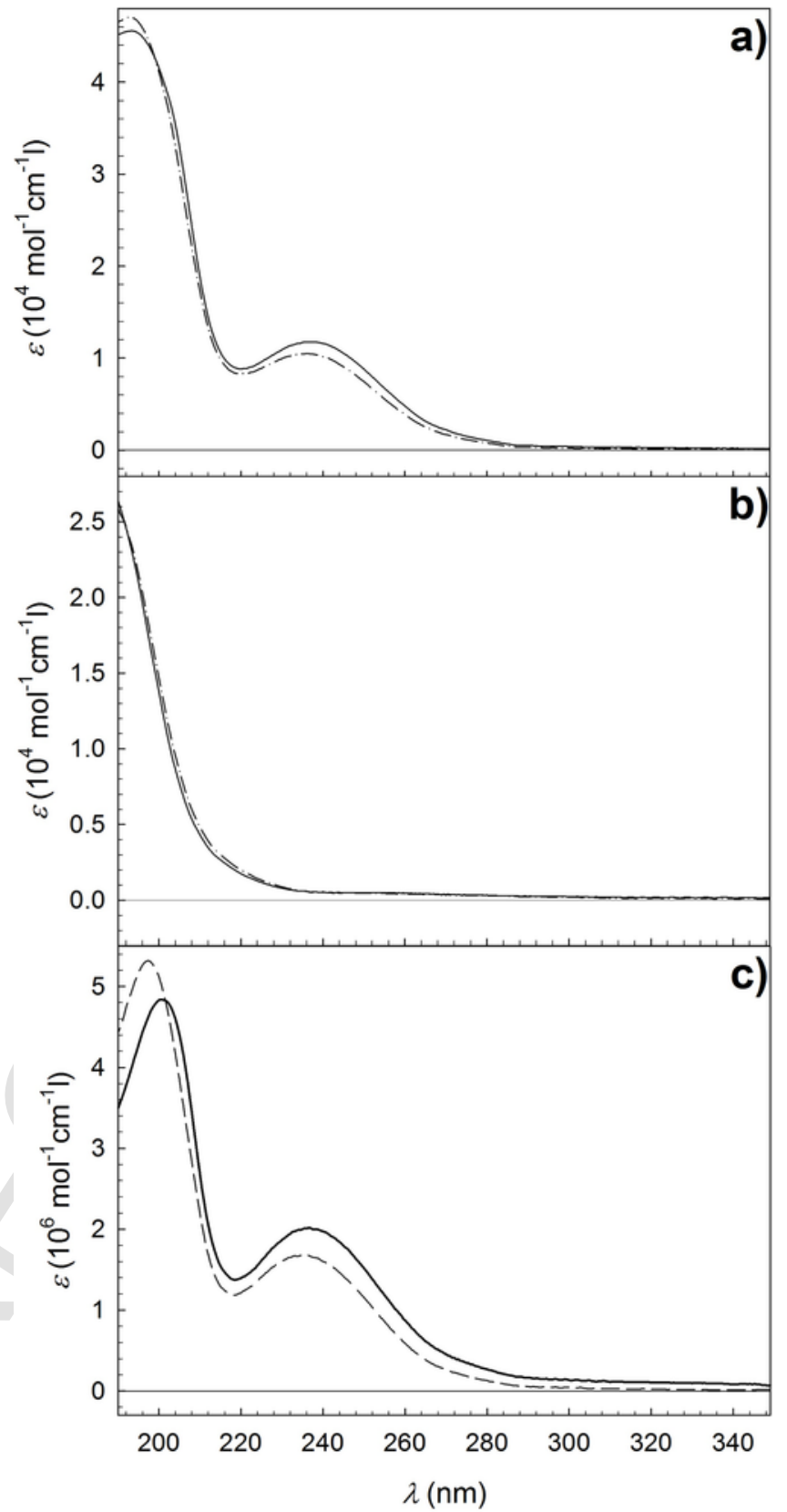

Fig. 2. UV absorption spectra recorded at 20 (bold line) and $60{ }^{\circ} \mathrm{C}$ (dashed line) of solutions of a) $5.0 \times 10^{-3} \mathrm{M}$ RGD-tbutPhC; b) $5.0 \times 10^{-3} \mathrm{M}$ RGD; c) $2.0 \times 10^{-3} \mathrm{M}$ H-tbutPhC. All the solutions were prepared in carbonate/bicarbonate buffer at $\mathrm{pH} 10.0$.

strong positive band at $250 \mathrm{~nm}$ (Fig. 3c) was associated to the formation of tubes [48], revealing a strong chiral arrangement of the transition dipole moments of the chromophores responsible of the UV band at higher wavelengths. The $\mathrm{CD}$ profile was very similar in shape to that of RGD-tbutPhC, suggesting that a similar chiral intermolecular coupling of the transition electric dipole moment occurred both in the peptide containing derivative and the precursor. The spectrum recorded on a $5.0 \times 10^{-3} \mathrm{M}$ solution of RGD (Fig. 3b) showed the presence of a negative peak at $205 \mathrm{~nm}$ that was not sensitive to temperature change (Fig. 3c). Roughly in the same region RGD-tbutPhC showed a more intense negative peak which decreased upon in- 


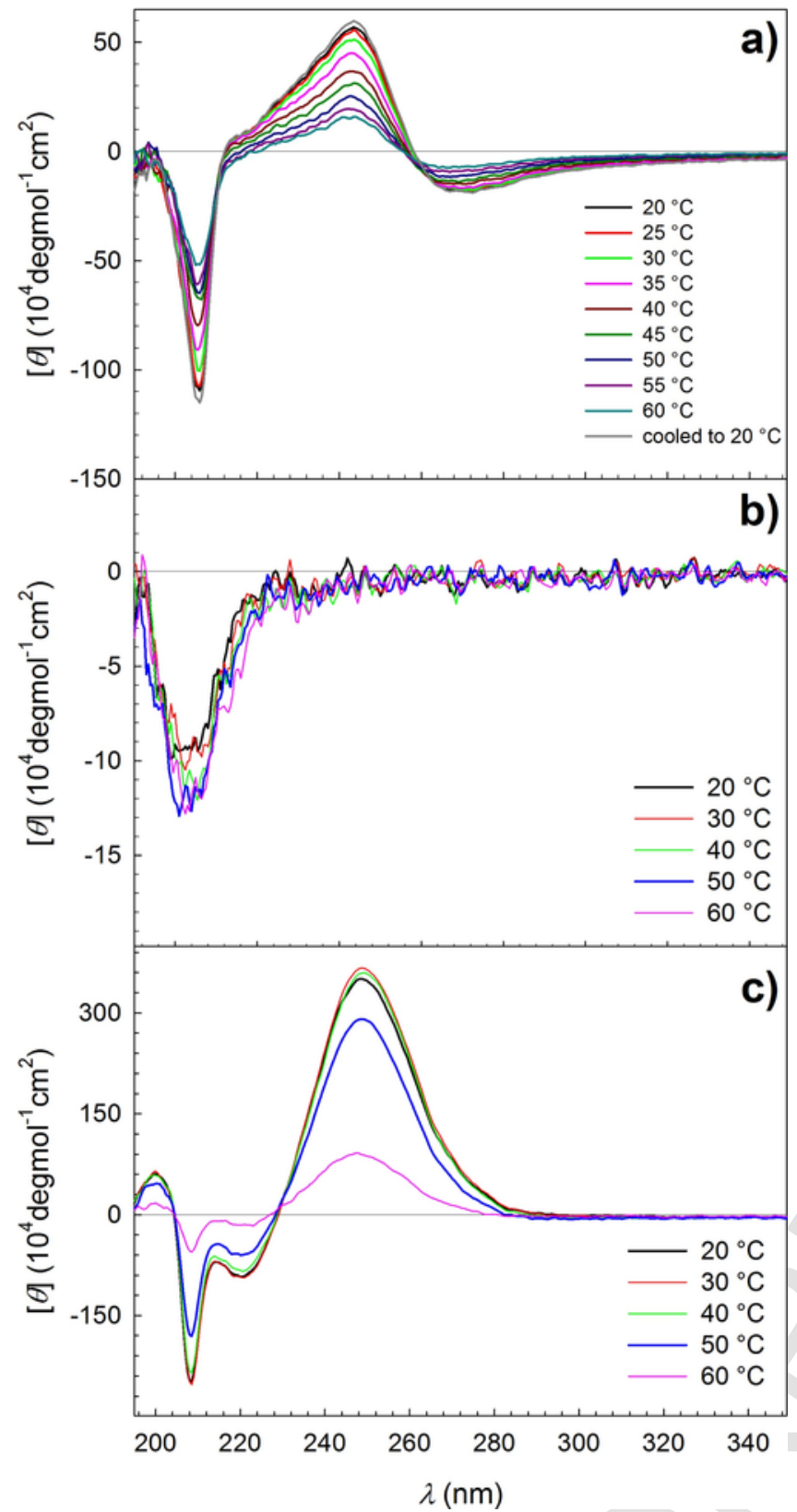

Fig. 3. $\mathrm{CD}$ spectra as a function of temperature of solutions of a) $5.0 \times 10^{-3} \mathrm{M}$ RGD-tbutPhC; b) $5.0 \times 10^{-3} \mathrm{M}$ RGD and c) $2.0 \times 10^{-3} \mathrm{M}$ H-tbutPhC. All the solutions were prepared in carbonate/bicarbonate buffer at $\mathrm{pH} 10.0$.

crease of temperature. The presence of a similar band in the H-tbut$\mathbf{P h C}$ sample was attributable to interacting phenylamide residues. It is highly likely that the interactions of these residues were the main responsible for this band also in the RGD-substituted derivative.

The direct imaging via cryo-TEM revealed that the RGD-tbutPhC aggregates were formed by twisted ribbons as dominant morphology (Figs. 4 and S3). These ribbons were characterized by length up to $5 \mu \mathrm{m}$, width of $25 \pm 5 \mathrm{~nm}$ and twist pitch of $145 \pm 9 \mathrm{~nm}$ (Figs. S4-S5). It was possible to notice that a small fraction of ribbons merged in wider ribbons that eventually rearrange into a helical structure sometimes closed to form tubes (Figs. 4b, S3d-f). The diameter of the helical tubes was found to be ca. $100 \mathrm{~nm}$.

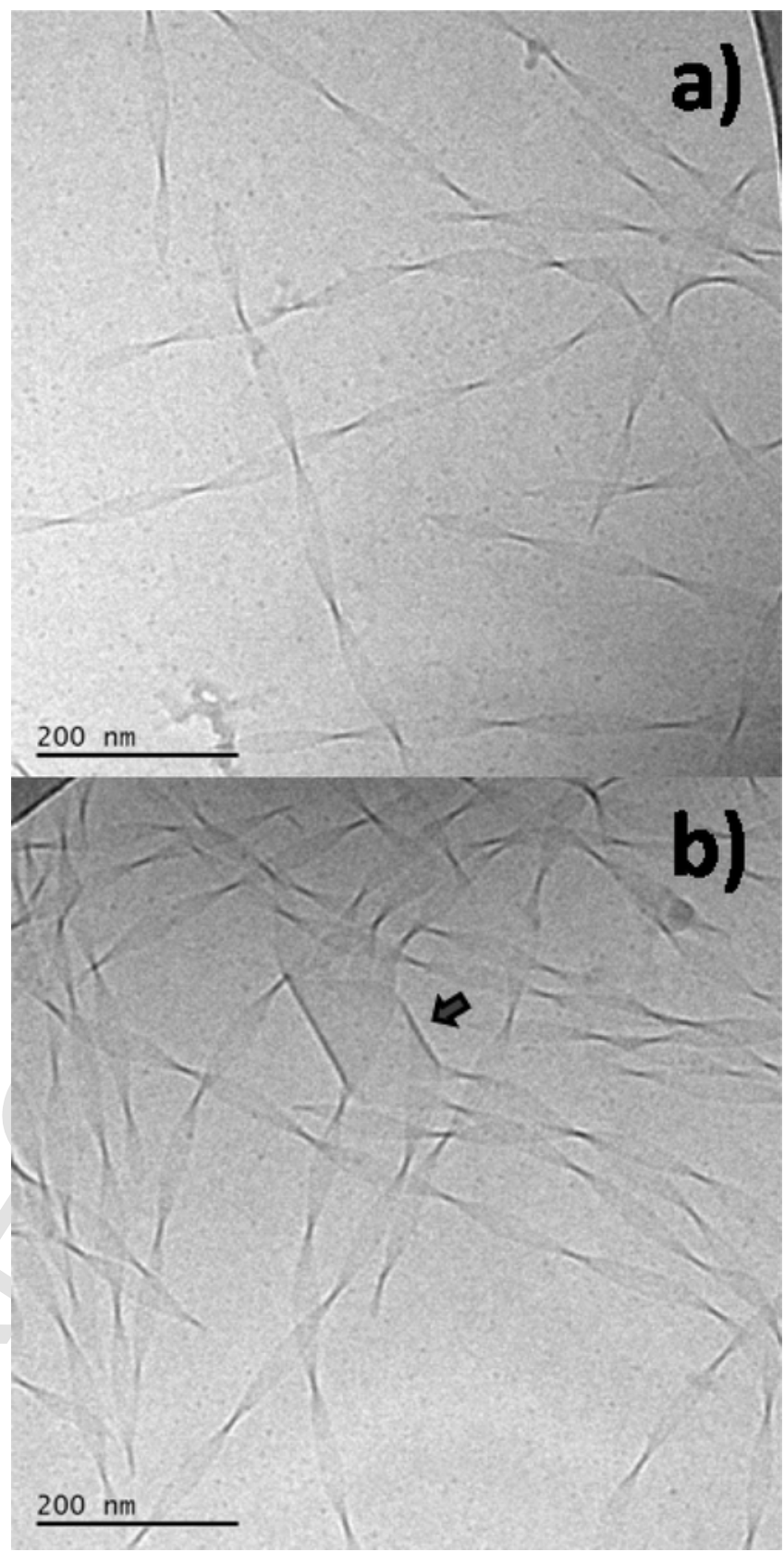

Fig. 4. Cryo-TEM images of RGD-tbutPhC $5.0 \times 10^{-3} \mathrm{M}$ in buffer $(\mathrm{pH}=10.0)$. The arrow indicates the merging of ribbons in helical tubes in panel $b$.

A complementary analysis of the structure of the RGD-tbutPhC aggregates was performed by using SAXS. Intensity profiles at three different temperatures were recorded (Fig. 5a). In all cases the curves showed a slope in the $\log -\log$ plot corresponding to the I $\propto$ q-2 trend typical of layered structures (Fig. S6) [57-59] in the intermediate $q$ range. The Guinier plot for flat objects in the range $0.4-0.8 \mathrm{~nm}^{-1}$ allowed us to determine an $R_{g t}$ value of $1.3 \pm 0.3 \mathrm{~nm}$ (Fig. S7), from which a thickness $T$ of the ribbon of $4.5 \mathrm{~nm}$ was estimated. The slope progressively changed at lower $q$ values and approached the dependence I $\propto$ q-1 typical for rod-like structures at the lowest accessible scattering angles. These results confirmed that flat ribbons were formed in the samples. 


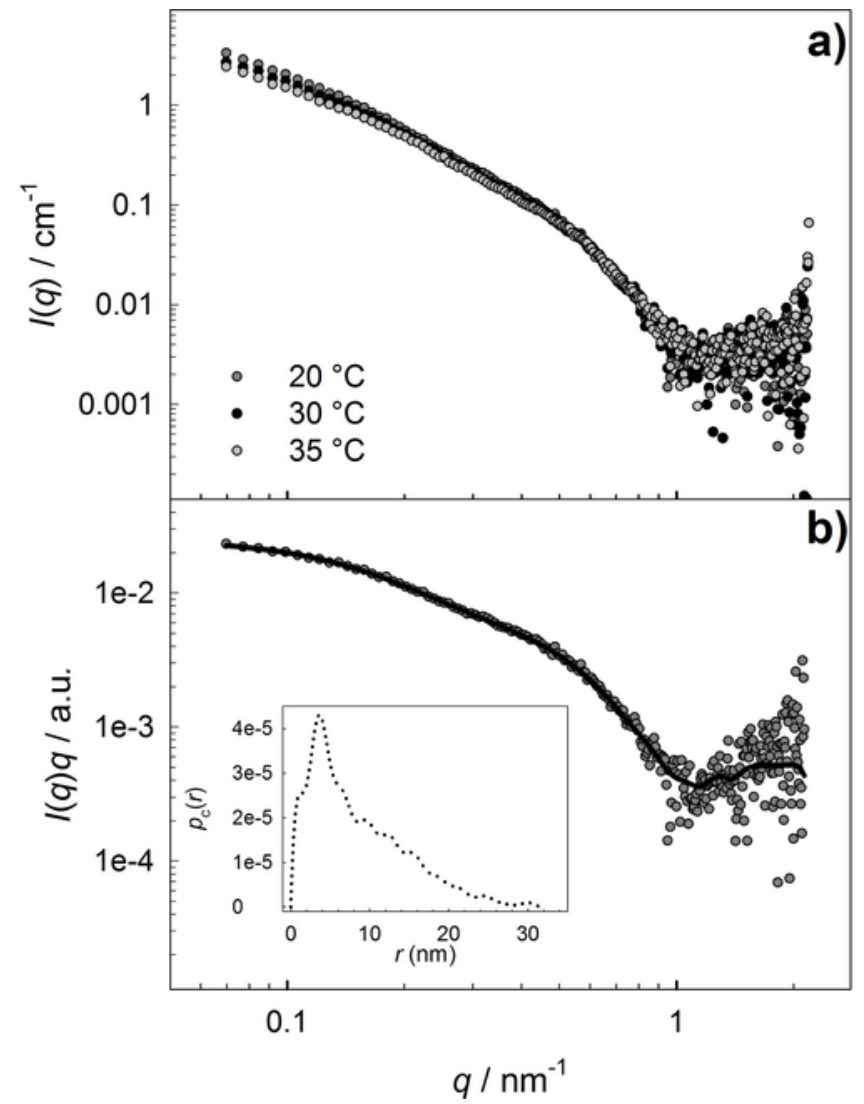

Fig. 5. SAXS data and interpretations of $5.0 \times 10^{-3} \mathrm{M}$ RGD-tbutPhC solutions in carbonate/bicarbonate buffer at $\mathrm{pH}=10.0$ : a) SAXS patterns recorded at 20,30 and $35^{\circ} \mathrm{C}$; b) experimental (grey circles) and IFT best fitting (black line) $I(q) q$ curve with corresponding cross-section pair distance distribution function $p_{\mathrm{c}}(r)$ in the inset.

The IFT method (Fig. 5b) was performed on the $I(q) q$ curve to extract the cross-section pair correlation function $p_{c}(r)$ of the ribbon. The extracted function provided a $D_{m c}$ of $30 \mathrm{~nm}$, consistent with the ribbon width value estimated by cryo-TEM (the Guinier plot for the cross-section was not reported due to the little number of data points). The SAXS pattern was also analysed by using the form factor of a homogeneous infinitely long parallelepiped to model the scattering of the observed ribbons. Although twist was not considered in the model, we obtained that the intensity calculated for a parallelepiped of thickness $4.5 \pm 0.1 \mathrm{~nm}$ and width $26.0 \pm 1.0 \mathrm{~nm}$ was able to reproduce the experimental profile (Fig. S8).

The formation of the twisted ribbons could be explained on the basis of previous examples reported in the literature $[60,61]$ and the Tilted Chiral Lipid Bilayer (TCBL) theory $[62,63]$.

In the case of RGD-tbutPhC, we propose that the molecules self-assemble into a bilayer to form the ribbons. Reasonably, in the bilayer, the tert-butyl-phenyl groups would be oriented towards the interior, while the hydrophilic peptide moieties would be located on the surface. With a thickness of the ribbon of $4.5 \mathrm{~nm}$ as estimated from SAXS it is likely that the tert-butyl-phenyl moieties overlap in the bilayer (Fig. 6). This type of molecular organization would thus allow for a stabilization of the supramolecular aggregate by $\pi-\pi$ interactions involving the aromatic moieties and on the same time would explain the intense CD signal of the ribbons samples. This arrangement could be kept up to the edges of the ribbon where the molecules could be oriented with the hydrophilic face toward the solvent to minimize the surface energy. In spite of this, the surface energy would still be higher at the edges compared to the main ribbon surface, the latter being covered by RGD groups, which are the most hydrophilic moieties of the molecules. In light of this, merging and fusion of the thin twisted ribbons into wider helical ones is expected and sometimes observed (see cryo-TEM micrographs of Fig. $4 \mathrm{~b}$ and $\mathrm{S} 3 \mathrm{~d}-\mathrm{f}$ ), since this process can reduce the lateral surface energy. A wide ribbon should transform into an helical ribbon through twisting and bending in order to afford the morphological stability. [57,65-67]. Eventually, according to TCLB theory $[62,63]$ the helical ribbons might close into tubules, in order to further reduce the lateral surface free energy. This process has already been observed in studies of the kinetics of formation of supramolecular tubes. [57] Accordingly, it is reasonable to believe that the observed RGD-tbutPhC twisted ribbons are unstable and that nanotubes could be the final structure of the long-time evolution of the system.

The formation of twisted ribbons by self-assembly of peptide amphiphiles, has already been observed. For example, they have been reported for di-alkyl peptide amphiphiles, although with very larger sizes (width $1.2 \mu \mathrm{m}$ and pitch $18 \mu \mathrm{m}$ ), a multibilayer structure and in coexistence with other aggregates [64]. It is worth mentioning that the formation of chiral superstructures like twisted ribbons is promoted by specific interactions involving the chiral groups of the amphiphiles. In the case of peptide amphiphiles, the involvement of the peptide moiety is in many cases crucial to induce the self-assembly into chiral organizations. In our case, the $\mathrm{CD}$ results demonstrated that the interactions between the RGD groups within the chiral aggre-

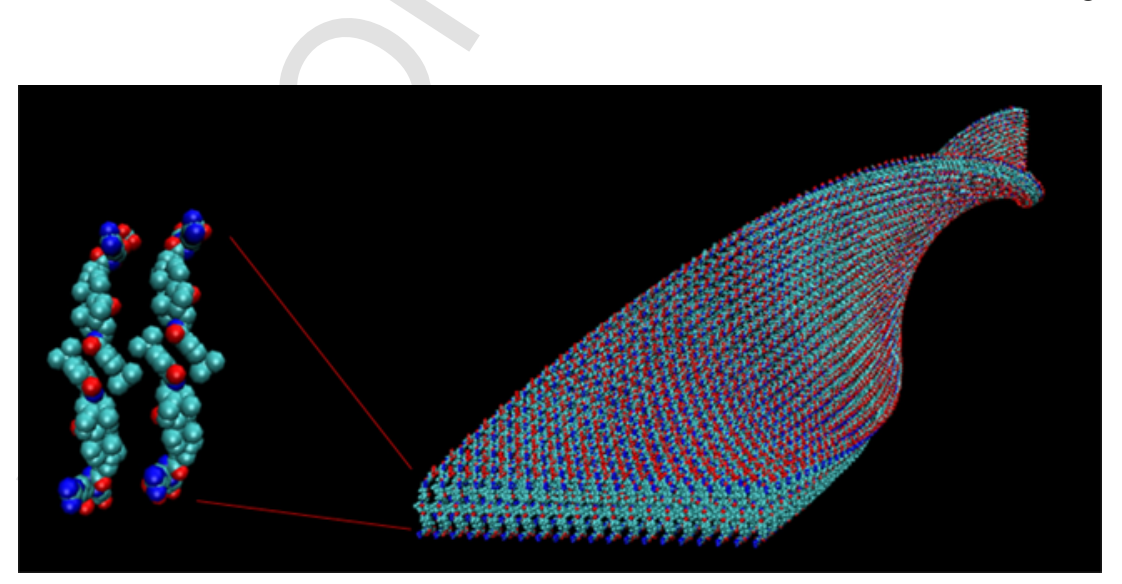

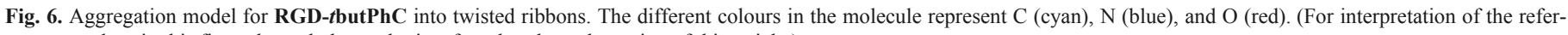
ences to colour in this figure legend, the reader is referred to the web version of this article.) 
gates seem to be very weak. This means that these groups are relatively free and by that available for interactions with the surrounding environment, which could be crucial for the applications.

\section{Conclusions}

In this work, a novel bile salt derivative bearing an aromatic moiety on the steroidal skeleton and the biologically active RGD sequence was synthesized. The purpose was to obtain a peptide-based amphiphile with a unique and possibly unusual self-assembly, due to presence of the rigid amphiphilic structure of the derivative. The molecule self-assembled in mild alkaline solutions in long twisted ribbons characterized by width, thickness and twist pitch with a very low degree of polydispersity. The circular dichroism measurements clearly revealed a chiral arrangement of the molecules and a bilayered structure, in which the aromatic moieties are positioned in the interior and the RGD residue at the bilayer/water interface, was proposed. The nanostructure is significantly different from those generally provided by conventional RGD-containing amphiphiles, which has been observed to form fibers with a circular cross-section. According to the literature, features like morphology, rigidity, epitope spacing and periodicity determine the performance of nanostructures, as they dramatically influence cell adhesion and signaling [27,28]. Bile salt-based peptide amphiphiles are therefore useful to exploit for the preparation of nanostructures with well-defined monodisperse morphologies and epitope distributions, which in turn pave the way towards designing of new non-trivial RGD decorated nanoaggregates.

\section{Conflict of interest}

The authors report no conflicts of interest in this work.

\section{Acknowledgments}

The authors thank Gunnel Klarsson for her skillful assistance with the cryo-TEM experiments. Emilia Severoni is also acknowledged for some CD measurements. This work benefited from SasView software, originally developed by the DANSE project under NSF award DMR-0520547. ESMI Project is acknowledged for financial support (E131100452).

\section{Appendix A. Supplementary data}

Supplementary data associated with this article can be found, in the online version, at http://dx.doi.org/10.1016/j.colsurfb.2017.07.084.

\section{References}

[1] G. Whitesides, J. Mathias, C. Seto, Molecular self-assembly and nanochemistry: a chemical strategy for the synthesis of nanostructures, Science 254 (1991) 1312-1319.

[2] E. Busseron, Y. Ruff, E. Moulin, N. Giuseppone, Supramolecular self-assemblies as functional nanomaterials, Nanoscale 5 (2013) 7098-7140.

[3] J.-M. Lehn, Toward complex matter: supramolecular chemistry and self-organization, Proc. Natl. Acad. Sci. 99 (2002) 4763-4768.

[4] S.I. Stupp, L.C. Palmer, Supramolecular chemistry and self-assembly in organic materials design, Chem. Mater. 26 (2014) 507-518.
[5] D.W.P.M. Lowik, E.H.P. Leunissen, M. van den Heuvel, M.B. Hansen, J.C.M. van Hest, Stimulus responsive peptide based materials, Chem. Soc. Rev. 39 (2010) 3394-3412.

[6] R.J. Mart, R.D. Osborne, M.M. Stevens, R.V. Ulijn, Peptide-based stimuli-responsive biomaterials, Soft Matter 2 (2006) 822-835.

[7] A. Dehsorkhi, V. Castelletto, I.W. Hamley, Self-assembling amphiphilic peptides, J. Pept. Sci. 20 (2014) 453-467.

[8] S. Cavalli, F. Albericio, A. Kros, Amphiphilic peptides and their cross-disciplinary role as building blocks for nanoscience, Chem. Soc. Rev. 39 (2010) 241-263.

[9] D.W.P.M. Lowik, J.C.M. van Hest, Peptide based amphiphiles, Chem. Soc. Rev. 33 (2004) 234-245.

[10] M.D. Pierschbacher, E. Ruoslahti, Cell attachment activity of fibronectin can be duplicated by small synthetic fragments of the molecule, Nature 309 (1984) $30-33$.

[11] E. Ruoslahti, M. Pierschbacher, New perspectives in cell adhesion: RGD and integrins, Science 238 (1987) 491-497.

[12] M. Seleci, D.A. Seleci, M. Ciftci, D. Odaci Demirkol, F. Stahl, S. Timur, T. Scheper, Y. Yagci, Nanostructured amphiphilic star-hyperbranched block copolymers for drug delivery, Langmuir 31 (2015) 4542-4551.

[13] B. Jeschke, J. Meyer, A. Jonczyk, H. Kessler, P. Adamietz, N.M. Meenen, M. Kantlehner, C. Goepfert, B. Nies, RGD-peptides for tissue engineering of articular cartilage, Biomaterials 23 (2002) 3455-3463.

[14] J. Boekhoven, S.I. Stupp, 25th anniversary article: supramolecular materials for regenerative medicine, Adv. Mater. 26 (2014) 1642-1659.

[15] V. Castelletto, R.M. Gouveia, C.J. Connon, I.W. Hamley, New RGD-peptide amphiphile mixtures containing a negatively charged diluent, Faraday Discuss. 166 (2013) 381-397.

[16] R.N. Shah, N.A. Shah, M.M. Del Rosario Lim, C. Hsieh, G. Nuber, S.I. Stupp, Supramolecular design of self-assembling nanofibers for cartilage regeneration, Proc. Natl. Acad. Sci. 107 (2010) 3293-3298.

[17] J.D. Hartgerink, E. Beniash, S.I. Stupp, Self-assembly and mineralization of peptide-amphiphile nanofibers, Science 294 (2001) 1684-1688.

[18] J. Kopeček, J. Yang, Smart self-assembled hybrid hydrogel biomaterials, Angew. Chem. Int. Ed. 51 (2012) 7396-7417.

[19] M. Goktas, G. Cinar, I. Orujalipoor, S. Ide, A.B. Tekinay, M.O. Guler, Self-assembled peptide amphiphile nanofibers and PEG composite hydrogels as tunable ECM mimetic microenvironment, Biomacromolecules 16 (2015) 1247-1258.

[20] J.H. Collier, J.S. Rudra, J.Z. Gasiorowski, J.P. Jung, Multi-component extracellular matrices based on peptide self-assembly, Chem. Soc. Rev. 39 (2010) 3413-3424.

[21] A. Dasgupta, J.H. Mondal, D. Das, Peptide hydrogels, RSC Adv. 3 (2013) 9117-9149.

[22] T. Pakalns, K.L. Haverstick, G.B. Fields, J.B. McCarthy, D.L. Mooradian, M. Tirrell, Cellular recognition of synthetic peptide amphiphiles in self-assembled monolayer films, Biomaterials 20 (1999) 2265-2279.

[23] G. Cheng, V. Castelletto, R.R. Jones, C.J. Connon, I.W. Hamley, Hydrogelation of self-assembling RGD-based peptides, Soft Matter 7 (2011) 1326-1333. 
[24] V. Castelletto, C.M. Moulton, G. Cheng, I.W. Hamley, M.R. Hicks, A. Rodger, D.E. Lopez-Perez, G. Revilla-Lopez, C. Aleman, Self-assembly of Fmoc-tetrapeptides based on the RGDS cell adhesion motif, Soft Matter 7 (2011) 11405-11415.

[25] A. Buxboim, I.L. Ivanovska, D.E. Discher, Matrix elasticity, cytoskeletal forces and physics of the nucleus: how deeply do cells 'feel' outside and in?, J. Cell Sci. 123 (2010) 297-308.

[26] S. Sur, F. Tantakitti, J.B. Matson, S.I. Stupp, Epitope topography controls bioactivity in supramolecular nanofibers, Biomater. Sci. 3 (2015) 520-532.

[27] R.K. Das, O.F. Zouani, C. Labrugère, R. Oda, M.-C. Durrieu, Influence of nanohelical shape and periodicity on stem cell fate, ACS Nano 7 (2013) 3351-3361.

[28] D.J. Welsh, P. Posocco, S. Pricl, D.K. Smith, Self-assembled multivalent RGD-peptide arrays - morphological control and integrin binding, Organ. Biomol. Chem. 11 (2013) 3177-3186.

[29] D. Madenci, S.U. Egelhaaf, Self-assembly in aqueous bile salt solutions, Curr. Opin. Colloid Interface Sci. 15 (2010) 109-115.

[30] L. Galantini, M.C. di Gregorio, M. Gubitosi, L. Travaglini, J.V. Tato, A. Jover, F. Meijide, V.H. Soto Tellini, N.V. Pavel, Bile salts and derivatives: rigid unconventional amphiphiles as dispersants, carriers and superstructure building blocks, Curr. Opin. Colloid Interface Sci. 20 (2015) 170-182.

[31] L. Galantini, N.V. Pavel, Collective diffusion and self-diffusion coefficients comparison to separate interactions and micellar size effects on ionic micelle diffusivities: cylindrical micelles of sodium taurodeoxycholate, J. Chem. Phys. 118 (2003) 2865-2872.

[32] A. Bonincontro, A.A. D'Archivio, L. Galantini, E. Giglio, F. Punzo, X-ray, electrolytic conductance, and dielectric studies of bile salt micellar aggregates, Langmuir 16 (2000) 10436-10443.

[33] A.A. D'Archivio, L. Galantini, E. Gavuzzo, E. Giglio, L. Scaramuzza, Possible models for the micellar aggregates of glycocholate and taurocholate salts from crystal structures, QELS, and CD measurements, Langmuir 12 (1996) 4660-4667.

[34] M. Gomez-Mendoza, M.L. Marin, M.A. Miranda, Photoactive bile salts with critical micellar concentration in the micromolar range, PCCP 18 (2016) 12976-12982.

[35] L. Travaglini, A. D’Annibale, M.C. di Gregorio, K. Schillén, U. Olsson, S. Sennato, N.V. Pavel, L. Galantini, Between peptides and bile acids self-assembly of phenylalanine substituted cholic acids, J. Phys. Chem. B 117 (2013) 9248-9257.

[36] L. Travaglini, A. D'Annibale, K. Schillen, U. Olsson, S. Sennato, N.V. Pavel, L. Galantini, Amino acid-bile acid based molecules: extremely narrow surfactant nanotubes formed by a phenylalanine-substituted cholic acid, Chem. Commun. 48 (2012) 12011-12013.

[37] L. Travaglini, M. Gubitosi, M.C. di Gregorio, N.V. Pavel, A. D'Annibale, M. Giustini, V.H. Soto Tellini, J. Vazquez Tato, M. Obiols-Rabasa, S. Bayati, L. Galantini, On the self-assembly of a tryptophan labeled deoxycholic acid, PCCP 16 (2014) 19492-19504.

[38] M. Gubitosi, L. Travaglini, M.C. di Gregorio, N.V. Pavel, J. Vázquez Tato, S. Sennato, U. Olsson, K. Schillén, L. Galantini, Tailoring supramolecular nanotubes by bile salt based surfactant mixtures, Angew. Chem. Int. Ed. 54 (2015) 7018-7021.
[39] M. Gubitosi, L. Travaglini, A. D’Annibale, N.V. Pavel, J. Vázquez Tato, M Obiols-Rabasa, S. Sennato, U. Olsson, K. Schillén, L. Galantini, Sugar-bile acid-based bolaamphiphiles: from scrolls to monodisperse single-walled tubules, Langmuir 30 (2014) 6358-6366.

[40] M.C. di Gregorio, M. Varenik, M. Gubitosi, L. Travaglini, N.V. Pavel, A. Jover, F. Meijide, O. Regev, L. Galantini, Multi stimuli response of a single surfactant presenting a rich self-assembly behavior, RSC Adv. 5 (2015) 37800-37806.

[41] N. Manghisi, C. Leggio, A. Jover, F. Meijide, N.V. Pavel, V.H. Soto Tellini, J. Vázquez Tato, R.G. Agostino, L. Galantini, Catanionic tubules with tunable charge, Angew. Chem. Int. Ed. 49 (2010) 6604-6607.

[42] M.C. di Gregorio, N.V. Pavel, A. Jover, F. Meijide, J. Vazquez Tato, V.H. Soto Tellini, A. Alfaro Vargas, O. Regev, Y. Kasavi, K. Schillen, L. Galantini, pH sensitive tubules of a bile acid derivative: a tubule opening by release of wall leaves, Phys. Chem. Chem. Phys. 15 (2013) 7560-7566.

[43] H. Svobodova, V. Noponen, E. Kolehmainen, E. Sievanen, Recent advances in steroidal supramolecular gels, RSC Adv. 2 (2012) 4985-5007.

[44] M. Zhang, S. Strandman, K.C. Waldron, X.X. Zhu, Supramolecular hydrogelation with bile acid derivatives: structures, properties and applications, J. Mater. Chem. B 4 (2016) 7506-7520.

[45] U. Maitra, M. Maity, Supramolecular gels from Bile acid-Amino acid conjugates and their applications, Eur. J. Org. Chem. (2017), (n/a-n/a).

[46] M.C. di Gregorio, N.V. Pavel, J. Miragaya, A. Jover, F. Meijide, J. Vázquez Tato, V.H. Soto Tellini, L. Galantini, Catanionic gels based on cholic acid derivatives, Langmuir 29 (2013) 12342-12351.

[47] V.H. Soto Tellini, A. Jover, F. Meijide, J. Vázquez Tato, L. Galantini, N.V. Pavel, Supramolecular structures generated by a p-tert-butylphenyl-amide derivative of cholic acid: from vesicles to molecular tubes, Adv. Mater. 19 (2007) $1752-1756$

[48] L. Galantini, C. Leggio, A. Jover, F. Meijide, N.V. Pavel, V.H. Soto Tellini, J.V. Tato, R. Di Leonardo, G. Ruocco, Kinetics of formation of supramolecular tubules of a sodium cholate derivative, Soft Matter 5 (2009) 3018-3025.

[49] M. Bodanszky, Principles of Peptide Synthesis, Springer Science \& Business Media, 2012.

[50] R. Pascal, R. Sola, Preservation of the protective group under alkaline conditions by using $\mathrm{CaCl} 2$. Applications in peptide synthesis, Tetrahedron Lett. 39 (1998) 5031-5034.

[51] A. Kelleman, M.D. Mattern, M. Goodman, Incorporation of thioether building blocks into an $\alpha \mathrm{v} \beta 3$-specific RGD peptide: synthesis and biological activity, Pept. Sci. 71 (2003) 686-695.

[52] V.H.T.J. Vasquez Tato, J.V. Trillo, M. Alvarez, A. Antelo, J. Carrazana, A. Jover, F. Meijide, Spain Patent P2005 01843, 2005.

[53] J.R. Bellare, H.T. Davis, L.E. Scriven, Y. Talmon, Controlled environment vitrification system: an improved sample preparation technique, J. Electron Microsc. Tech. 10 (1988) 87-111.

[54] A.P. Hammersley, S.O. Svensson, M. Hanfland, A.N. Fitch, D. Hausermann, Two-dimensional detector software: from real detector to idealised image or two-theta scan, High Pressure Res. 14 (1996) 235-248. 
[55] P. Mittelbach, G. Porod, Small angle X-ray scattering by dilute colloid systems. The calculation of scattering curves for parallelepipeds, Acta Phys. Austriaca 14 (1961) 185-211.

[56] M.V. Petoukhov, D. Franke, A.V. Shkumatov, G. Tria, A.G. Kikhney, M. Gajda, C. Gorba, H.D.T. Mertens, P.V. Konarev, D.I. Svergun, New developments in the ATSAS program package for small-angle scattering data analysis, J. Appl. Crystallogr. 45 (2012) 342-350.

[57] L. Ziserman, H.-Y. Lee, S.R. Raghavan, A. Mor, D. Danino, Unraveling the mechanism of nanotube formation by chiral self-assembly of amphiphiles, J. Am. Chem. Soc. 133 (2011) 2511-2517.

[58] T.J. Moyer, H. Cui, S.I. Stupp, Tuning nanostructure dimensions with supramolecular twisting, J. Phys. Chem. B 117 (2013) 4604-4610.

[59] I.W. Hamley, A. Dehsorkhi, V. Castelletto, Self-assembled arginine-coated peptide nanosheets in water, Chem. Commun. 49 (2013) 1850-1852.

[60] S.-C. Lin, R.-M. Ho, C.-Y. Chang, C.-S. Hsu, Hierarchical superstructures with control of helicity from the self-assembly of chiral bent-core molecules, Chem.-A Eur. J. 18 (2012) 9091-9098
[61] A. Insuasty, C. Atienza, J.L. Lopez, N. Martin, Supramolecular pentapeptide-based fullerene nanofibers: effect of molecular chirality, Chem. Commun. 51 (2015) 10506-10509.

[62] O.-Y. Zhong-can, L. Ji-xing, Helical structures of tilted chiral lipid bilayers viewed as cholesteric liquid crystals, Phys. Rev. Lett. 65 (1990) 1679-1682.

[63] Z.-c. Ou-Yang, J. Liu, Theory of helical structures of tilted chiral lipid bilayers, Phys. Rev. A 43 (1991) 6826-6836.

[64] R. Oda, I. Huc, M. Schmutz, S.J. Candau, F.C. MacKintosh, Tuning bilayer twist using chiral counterions, Nature 399 (1999) 566-569.

[65] E.T. Pashuck, S.I. Stupp, Direct observation of morphological tranformation from twisted ribbons into helical ribbons, J. Am. Chem. Soc. 132 (2010) $8819-8821$

[66] A. Brizard, C. Aimé, T. Labrot, I. Huc, D. Berthier, F. Artzner, B. Desbat, R. Oda, Counterion, temperature, and time modulation of nanometric chiral ribbons from gemini-tartrate amphiphiles, J. Am. Chem. Soc. 129 (2007) 3754-3762.

[67] T. Shimizu, M. Hato, Self-assembling properties of synthetic peptidic lipids, Biochim. Biophys. Acta (BBA) - Biomembr. 1147 (1993) 50-58. 